\title{
Susceptibility to Hepatotoxicity in Transgenic Mice That Express a Dominant-Negative Human Keratin 18 Mutant
}

\author{
Nam-On Ku, Sara A. Michie, ${ }^{\star}$ Roy M. Soetikno, Evelyn Z. Resurreccion, ${ }^{\star}$ Rosemary L. Broome, ${ }^{\ddagger}$ Robert G. Oshima, ${ }^{\S}$ \\ and M. Bishr Omary \\ Department of Medicine, *Pathology, and ${ }^{\ddagger}$ Veterinary Medicine VA Palo Alto Health Care System, 111-G.I., Palo Alto, California 94304; \\ and the Digestive Disease Center, Stanford University School of Medicine; and ${ }^{\S}$ The Burnham Institute, La Jolla, California 92037
}

\begin{abstract}
Keratins 8 and $18(\mathrm{~K} 8 / 18)$ are intermediate filament phosphoglycoproteins that are expressed preferentially in simpletype epithelia. We recently described transgenic mice that express point-mutant human K18 (Ku, N.-O., S. Michie, R.G. Oshima, and M.B. Omary. 1995. J. Cell Biol. 131:13031314) and develop chronic hepatitis and hepatocyte fragility in association with hepatocyte keratin filament disruption. Here we show that mutant K18 expressing transgenic mice are highly susceptible to hepatotoxicity after acute administration of acetaminophen $(400 \mathrm{mg} / \mathrm{Kg})$ or chronic ingestion of griseofulvin $(1.25 \% \mathrm{wt} / \mathrm{wt}$ of diet). The predisposition to hepatotoxicity results directly from the keratin mutation since nontransgenic or transgenic mice that express normal human K18 are more resistant. Hepatotoxicity was manifested by a significant difference in lethality, liver histopathology, and biochemical serum testing. Keratin glycosylation decreased in all griseofulvin-fed mice, whereas keratin phosphorylation increased dramatically preferentially in mice expressing normal K18. The phosphorylation increase in normal K18 after griseofulvin feeding appears to involve sites that are different to those that increase after partial hepatectomy. Our results indicate that hepatocyte intermediate filament disruption renders mice highly susceptible to hepatotoxicity, and raises the possibility that K18 mutations may predispose to drug hepatotoxicity. The dramatic phosphorylation increase in nonmutant keratins could provide survival advantage to hepatocytes. (J. Clin. Invest. 1996. 98: 1034-1046.) Key words: griseofulvin • acetaminophen • glycosylation • phosphorylation • liver
\end{abstract}

\section{Introduction}

Intermediate filament (IF) ${ }^{1}$ proteins form one of the three major cytoskeletal protein groups, and are preferentially express in higher eukaryotes (reviewed in references 1-3). Although the cell biological function(s) of IF proteins remain poorly defined, evidence of their importance in a variety of human dis-

\footnotetext{
Address reprint requests to Nam-On Ku and all other correspondence to Bishr Omary, Palo Alto VA Medical Center, 3801 Miranda Avenue, 111-GI, Palo Alto, CA 94304.

Received for publication 25 January 1996 and accepted in revised form 13 June 1996.
}

J. Clin. Invest.

(C) The American Society for Clinical Investigation, Inc. 0021-9738/96/08/1034/13 \$2.00

Volume 98, Number 4, August 1996, 1034-1046 eases is accumulating at a rapid pace (reviewed in references 4-7). The diversity of the IF associated human diseases reflects the diversity and tissue-specific expression of the large cytoplasmic IF protein family. Examples of the tissue-specific expression of IF proteins include keratins in epithelia, desmin in muscle, and neurofilaments in neuronal cells. To date, mutations in 11 of the more than 20 keratins (K1-K20) are known to cause human disease, as in epidermolysis bullosa simplex (EBS) (K5, K14); epidermolytic hyperkeratosis and epidermal nevi (K1/K10 and $\mathrm{K} 10$, respectively); epidermolytic palmoplantar keratoderma (K9); ichthyosis bullosa of Siemens (K2e); pachyonychia congenita (K6, K16, and K17); and white sponge nevus (K4 and K13) (see references 8 and 9 for K16/17 and K6, respectively; 10 and 11 for K4 and K13, respectively; and 4-7 for K5, K14, K1, K10, K9, K2 mutations). Furthermore, mutations in neurofilament-H have been identified in a small number of sporadic cases of amyotrophic lateral sclerosis (12).

In contrast to the above mentioned epidermal keratins, mutations in simple epithelial-type keratins have not been associated with a human disease to date. These latter keratins include K8, K18, K19, and K20, which are expressed in variable combinations in glandular tissues such as liver, exocrine pancreas and intestine (1-3). Despite the lack of a human disease association with simple epithelial keratins, several animal models as well as the epidermal keratin diseases identified to date suggest that one or more disease are likely to be identified as simple epithelial keratin human disease(s). The relevance and importance of animal models in identifying IF related human diseases is demonstrated by the expression of a truncated K14 in transgenic mice (13) with a resultant phenotype that ultimately led to the identification of epidermolysis bullosa simplex as the first described human IF-related disease (14). In the case of simple epithelial keratin animal models, K8-null mice bleed into their livers and die at a late embroynic stage (15) or develop colitis, colonic hyperplasia, and rectal prolapse (16) depending on the genetic background of the mice. Furthermore, ectopic expression of epidermal keratins in pancreatic islet cells (17) or in hepatocytes (18) results in keratin filament disruption in these cells and development of diabetes or chronic hepatitis, respectively. In addition, we recently described the generation of transgenic mice that express human $\mathrm{K} 18$ that is mutated at a highly conserved arginine residue (arg89 to cys) (19). This arg is conserved among many IF proteins, and is a hot mutation spot in several of the epidermal keratin associated human diseases described to date (4-7). Mice expressing the arg mutant human K18, but not wild-type

1. Abbreviations used in this paper: EBS, epidermolysis bullosa simplex; Emp, Empigen BB; GF, griseofulvin; IF, intermediate filament(s); K, keratin; N, normal nontransgenic mice; WT, wild type. 
human K18 (20), develop chronic hepatitis and increased hepatocyte fragility which led us to hypothesize that mutations in human K18 may cause or predispose to chronic or acute "idiopathic" liver disease (19).

The K18 arg mutation is associated with increased basal phosphorylation and glycosylation of K8/18 in transfected cells or transgenic mice expressing the K18 mutant protein, as compared with parallel systems that express wild-type (WT) K18 (19). Alterations in normal K8/18 glycosylation and/or phosphorylation are associated with a number of cellular stresses such as heat or virus infection (21), or mitotic arrest (22). Increased phosphorylation of K8/18 also occurs during the $\mathrm{S}$ and G2/M phases of the cell cycle (23). In the case of K18 phosphorylation, there is a 3-4-fold increase in phospho-ser52-K18 during mitosis as determined by immunofluorescence staining of cells or immunoblotting of cell lysates using a phospho-K18 epitope-specific antibody (24). In addition, chronic administra- tion of griseofulvin to normal nontransgenic mice results in cytoplasmic hyalin deposition (termed Mallory bodies) $(25,26)$ and hepatotoxicity $(27,28)$, with increased phosphorylation of mouse $\mathrm{K} 8 / 18(29,30)$.

Given that many drugs are metabolized by the liver and can in some instances cause significant hepatotoxicity (reviewed in references 31-34), we compared the effect of the two hepatotoxins griseofulvin and acetaminophen in transgenic mice that express arg-mutant or wild-type human $\mathrm{K} 18$, or in nontransgenic mice. We also examined the relative phosphorylation and glycosylation of K8/18 in the presence or absence of griseofulvin. Here we show that transgenic mice that express arg-mutant human K18 are significantly more susceptible to griseofulvin or acetaminophen induced hepatotoxicity as compared to transgenic mice that express wild-type human K18 (at levels similar to or lower than mutant K18 levels) or nontransgenic mice. Griseofulvin results in a dramatic decrease in kera-
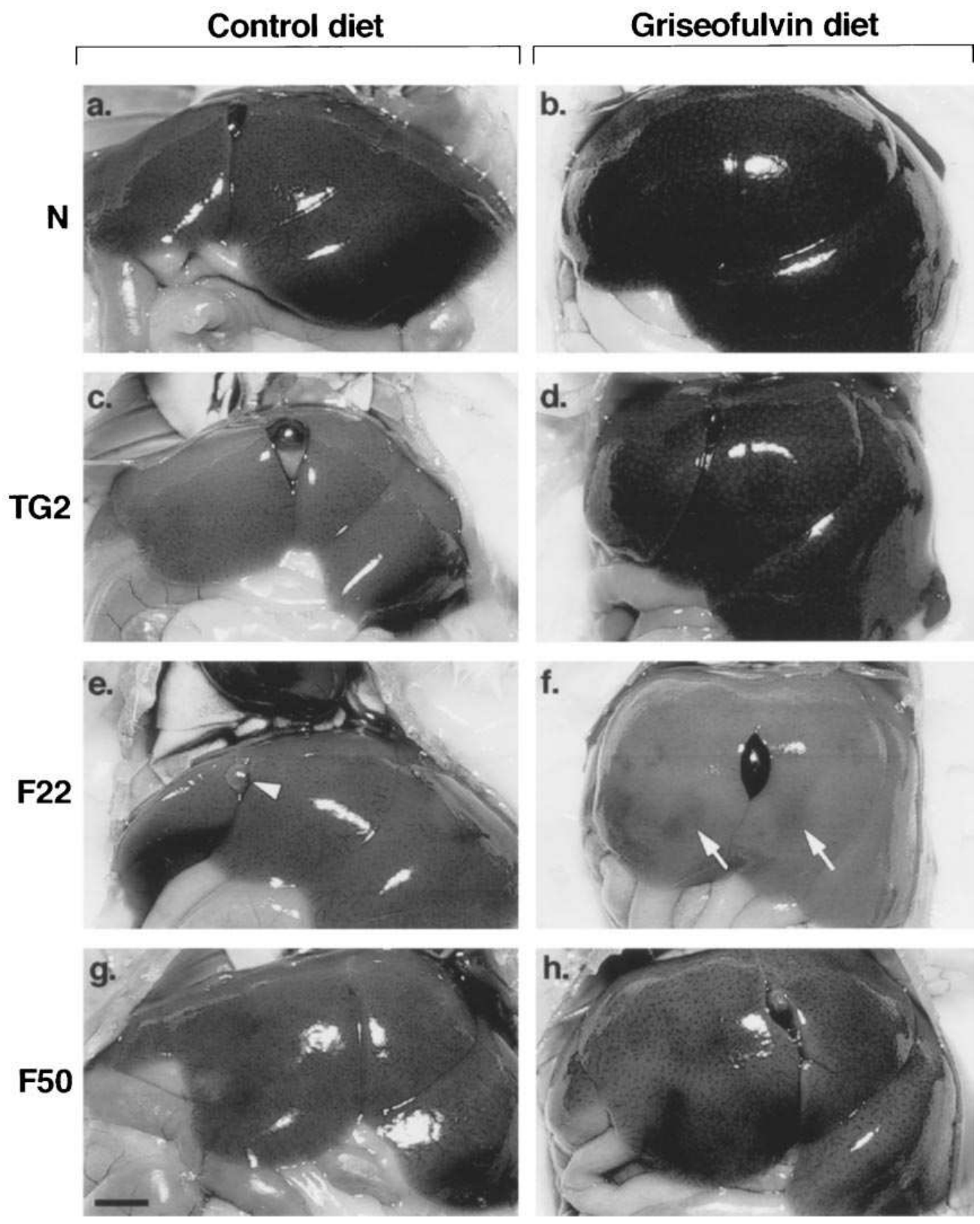

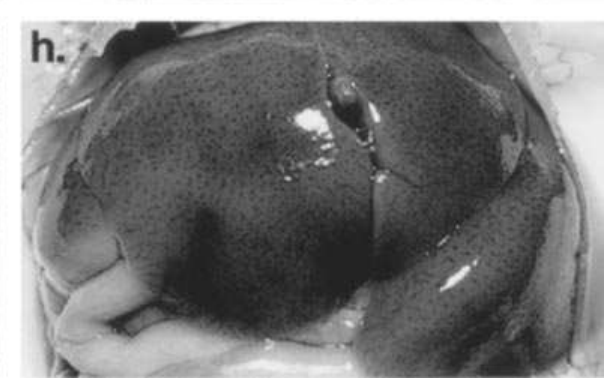

Figure 1. Gross appearance of livers from transgenic and nontransgenic mice fed control or griseofulvin diets for $17 \mathrm{~d}$. Normal nontransgenic mice $(\mathrm{N})$ or transgenic mice expressing wildtype $\mathrm{K} 18$ (TG2) or $\arg 89 \rightarrow$ cys mutant K18 (F22 and F50) were fed a powdered diet without or with $1.25 \%$ (wt/wt) griseofulvin. After $17 \mathrm{~d}$, mice were euthanized by $\mathrm{CO}_{2}$ inhalation followed by incision of the skin and peritoneum, then exposure of the liver (without manipulation) and photography. Note that the subcapsular meshworklike vascular markings in $\mathrm{N}$ and TG2 GF-fed mice became accentuated in association with liver hyperpigmentation. In contrast, livers from GF-fed F22 and F50 mice lose their vascular markings (F22, $f$ ) or manifest a punctate pattern $(\mathrm{F} 50, h)$ without hyperpigmentation. Arrowhead $(e)$ indicates gallbladder, and arrows indicate hemorrhagic areas $(f)$. Bar, $0.64 \mathrm{~cm}$. Identical magnification was used for all the panels. 
tin glycosylation in all mice tested, however, it significantly increased keratin phosphorylation only in mice that express WT K18. The increase in K18 phosphorylation after griseofulvin feeding does not appear to be related to hyperproliferation, as seen for example in mitosis-induced hyperphosphorylation of K8/18 after partial hepatectomy. The potential implications of these findings are discussed.

\section{Methods}

Biochemicals and antibodies. Reagents used were: uridine diphosphate (UDP)-[4-5- $\left.{ }^{3} \mathrm{H}\right]$-galactose (Dupont-New England Nuclear, Wilmington, DE); bovine milk galactosyltransferase and griseofulvin (GF) (Sigma Chemical Co., St. Louis, MO); and acetaminophen (McNeil, Fort Washington, PA). Antibodies used were: mouse monoclonal antibody $(\mathrm{mAb}) \mathrm{L} 2 \mathrm{~A} 1$ which recognizes human $\mathrm{K} 8 / 18$ and does not crossreact with mouse keratins (35), rat mAb Troma I (National Institute of Child Health and Human Development) which recognizes mouse K8, polyclonal rabbit antibody 8592 which was raised against human K8/18 but crossreacts with mouse keratins (19), rabbit antibody 3055 which specifically recognizes a phospho-K18 epitope that contains phospho-ser52 K18 (24), mAb PC-10 to proliferating cell nuclear antigen (PCNA) (Sigma Chemical Co.), and Texas red conjugated goat anti-rat or anti-mouse IgG (Molecular Probes, Eugene, OR). FVB/N normal (N) nontransgenic mice were purchased from Simenson Labs (Gilroy, CA).

Mice, drug administration, and partial hepatectomy. All animals were housed under strict infection control precautions. Sera from randomly chosen mice were tested monthly for several pathogens including murine viral hepatitis, without any evidence of infection noted. Three transgenic lines with FVB/N background (termed TG2, F22 and F50; see reference 19) were used which express normal human K18 (TG2) or an arg89 to cys mutant human K18 (F22 and F50 which represent two different founder lines). The relative protein ratio of endogenous mouse K18 to over-expressed human K18 is 3:1 (for TG2); 1:2 (for F22); and 1:1 (for F50) (19).

For the griseofulvin experiments, sex and age matched $(\sim 2$ mo old) nontransgenic (FVB/N strain), TG2, F22, or F50 mouse lines were fed powdered Lab Diet (PMI Feeds, Inc., St. Louis, MO) with or without $1.25 \% \mathrm{wt} / \mathrm{wt}$ griseofulvin (8 mice/line/type of feeding). The amount of GF chosen was less than the $2.5 \%$ used in Mallory body mouse-model studies (for example see references 26, 29, and 30) since preliminary experiments showed that doses in the $2.5 \%$ range appeared to be nearly uniformly fatal within $10 \mathrm{~d}$ in the mutant transgenic animals (not shown). In addition, GF is used here in the context of a mouse hepatotoxin rather that a Mallory body model. Four mice/line/food-type were analyzed after 7 or $17 \mathrm{~d}$ of feeding. Analysis entailed euthanasia by $\mathrm{CO}_{2}$ inhalation followed by collection of $0.6-1 \mathrm{ml}$ of blood by intracardiac puncture, resection and weighing of the total intact liver, then sectioning the liver for: routine hematoxylin-eosin staining after $10 \%$ formalin fixation, immunofluorescence staining or snap freezing in liquid $\mathrm{N}_{2}$ for subsequent immunoprecipitation of $\mathrm{K} 8 / 18$. Of note, keratin degradation was noted if tissues were stored at $-80^{\circ} \mathrm{C}$ before solubilization and immunoprecipitation (not shown).

Acetaminophen administration was done as described (36). 11 mice (sex matched, $\sim 2$ mo old) from each of the N, TG2, F22, and F50 lines were deprived of solid food for $3 \mathrm{~h}$ followed by infusion of acetaminophen by gavage $\left(400 \mathrm{mg} / \mathrm{Kg}\right.$, diluted with $\mathrm{H}_{2} \mathrm{O}$ to a final volume of $0.4-0.5 \mathrm{ml}$ ), then switching the water source to $5 \%$ dextrose- $\mathrm{H}_{2} \mathrm{O}$. After $2 \mathrm{~h}$, mice were allowed to feed ad lib and observed intermittently for the following $72 \mathrm{~h}$, then analyzed as done for the GF-fed mice. As a control, eleven additional F22 mice (the line that manifested the highest acetaminophen toxicity) were gavaged with $0.4 \mathrm{ml}$ of $\mathrm{H}_{2} \mathrm{O}$ then observed for $72 \mathrm{~h}$.

Partial $(65 \%)$ hepatectomy was performed essentially as described (37) by removing the lateral, and left and right median lobes. The resected liver was divided into several parts that were either fixed in $10 \%$ formalin for paraffin embedding then staining with antiPCNA antibody (38), or were snap frozen in liquid $\mathrm{N}_{2}$ for subsequent immunoprecipitation.

Histology grading and statistical analysis. Hematoxylin and eosin stained slides from GF-fed mice were examined by a pathologist (S.A.M.) without knowledge of the mouse line or type of diet. Grading was done by assigning scores of 0 (absent), 1 (mild), 2 (moderate), and 3 (severe) to the categories of anisocytosis, necrosis, cholestasis and fat. Each tabulated histology score represents the sum grade of the four categories.

Table I. Survival, Liver Weight and Histology Grade of Normal and Transgenic Mice

\begin{tabular}{|c|c|c|c|c|c|c|}
\hline \multirow[b]{2}{*}{ Type of mice and diet } & \multicolumn{2}{|c|}{ No. (total No.) } & \multicolumn{2}{|c|}{ Liver weight (grams) } & \multicolumn{2}{|c|}{ Histology grade } \\
\hline & day 7 & day 17 & day 7 & day 17 & day 7 & day 17 \\
\hline \multicolumn{7}{|l|}{ Normal } \\
\hline Control diet & $4(4)$ & $4(4)$ & $1.57 \pm 0.44$ & $1.41 \pm 0.25$ & $1.0 \pm 0$ & $1.0 \pm 0$ \\
\hline Griseofulvin diet & $4(4)$ & $4(4)$ & $2.57 \pm 0.49$ & $4.16 \pm 0.95$ & $5.3 \pm .5$ & $6.3 \pm 1.3$ \\
\hline \multicolumn{7}{|l|}{ Transgenic TG2 } \\
\hline Control diet & $4(4)$ & $4(4)$ & $1.48 \pm 0.32$ & $1.26 \pm 0.22$ & $0.8 \pm 0.5$ & $0.5 \pm 0.6$ \\
\hline Griseofulvin diet & $4(4)$ & $4(4)$ & $1.97 \pm 0.31$ & $3.72 \pm 0.38$ & $3.3 \pm 2.5$ & $6.8 \pm 2.1$ \\
\hline \multicolumn{7}{|l|}{ Transgenic F22 } \\
\hline Control diet & $4(4)$ & $4(4)$ & $1.64 \pm 0.04$ & $1.38 \pm 0.20$ & $2.5 \pm 0.6$ & $2.0 \pm .8$ \\
\hline Griseofulvin diet & $4(4)$ & $3(4)^{*}$ & $2.61 \pm 0.72$ & $3.34 \pm 0.11$ & $7.5 \pm 0.6^{\ddagger}$ & $9.7 \pm .6^{\S}$ \\
\hline \multicolumn{7}{|l|}{ Transgenic F50 } \\
\hline Control diet & $4(4)$ & $4(4)$ & $1.38 \pm 0.25$ & $1.41 \pm 0.22$ & $2.3 \pm .5$ & $2.0 \pm 0$ \\
\hline Griseofulvin diet & $4(4)$ & $1(4)^{*}$ & $2.72 \pm 0.31$ & 4.37 & $7.8 \pm 1.3^{\ddagger}$ & $10^{\S}$ \\
\hline
\end{tabular}

Histological findings of normal and transgenic mice: The indicated number of mice (sex matched, 2 mo old) were fed a control diet with or without $1.25 \%$ griseofulvin (wt/wt) for 7 or $17 \mathrm{~d}$. Mice were observed and supplemented with their corresponding diet on a daily basis. Livers were removed in total, after bleeding the mice, then immediately weighed wet. Histology grading was done as described in Methods. Deaths occurred on days 8, 9 , and 15 (F50) and on day 14 (F22). For statistical analysis, data from mutant transgenic (F22 + F50) were pooled and compared to data from TG2 and normal mice. $* P=0.036$ by Wilcoxon method for determining survival differences using Kaplan-Meier estimates of survival. ${ }^{\ddagger} P=0.007$ and ${ }^{\S} P=$ 0.001 by nonparametric Wilcoxon method. Hepatomegaly was statistically significant for all mouse lines after $17 \mathrm{~d}$ of GF feeding. 
Control diet
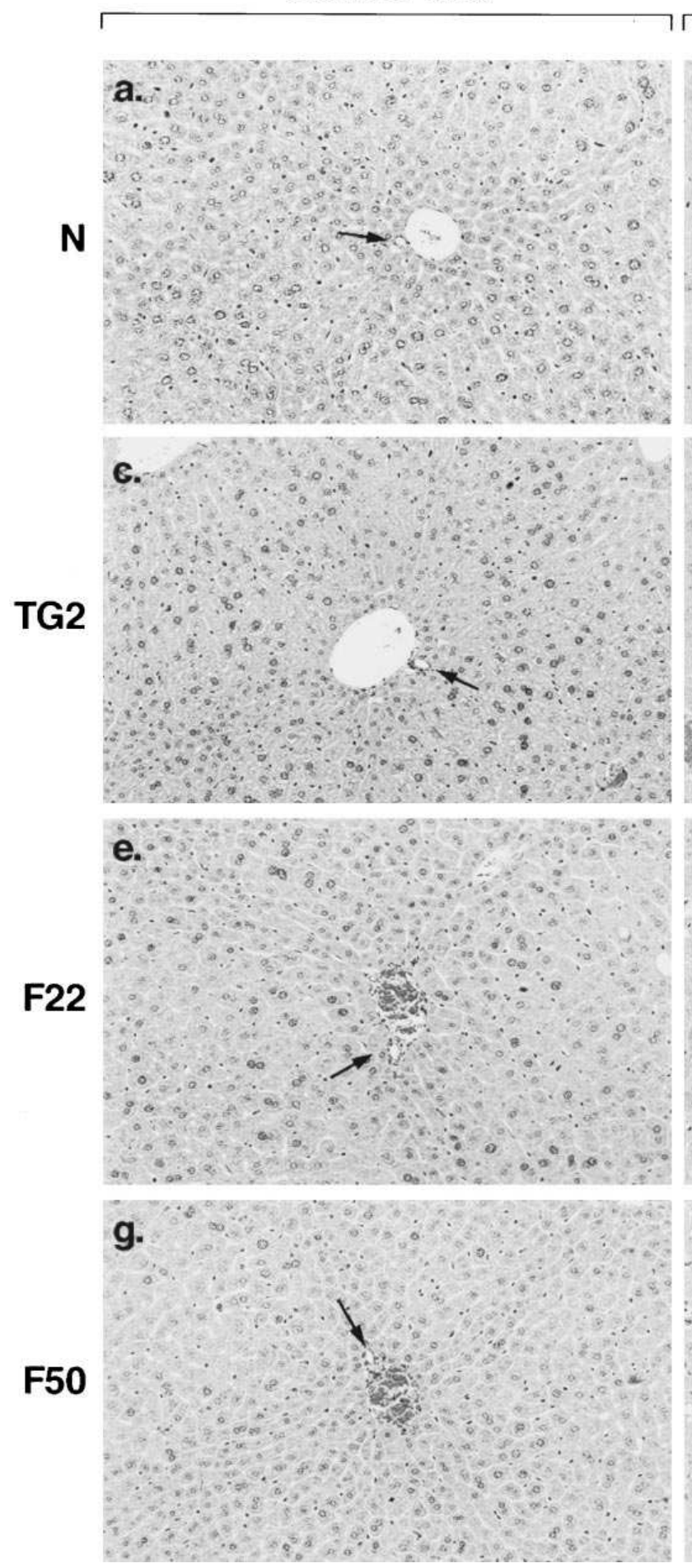

\section{Griseofulvin diet}
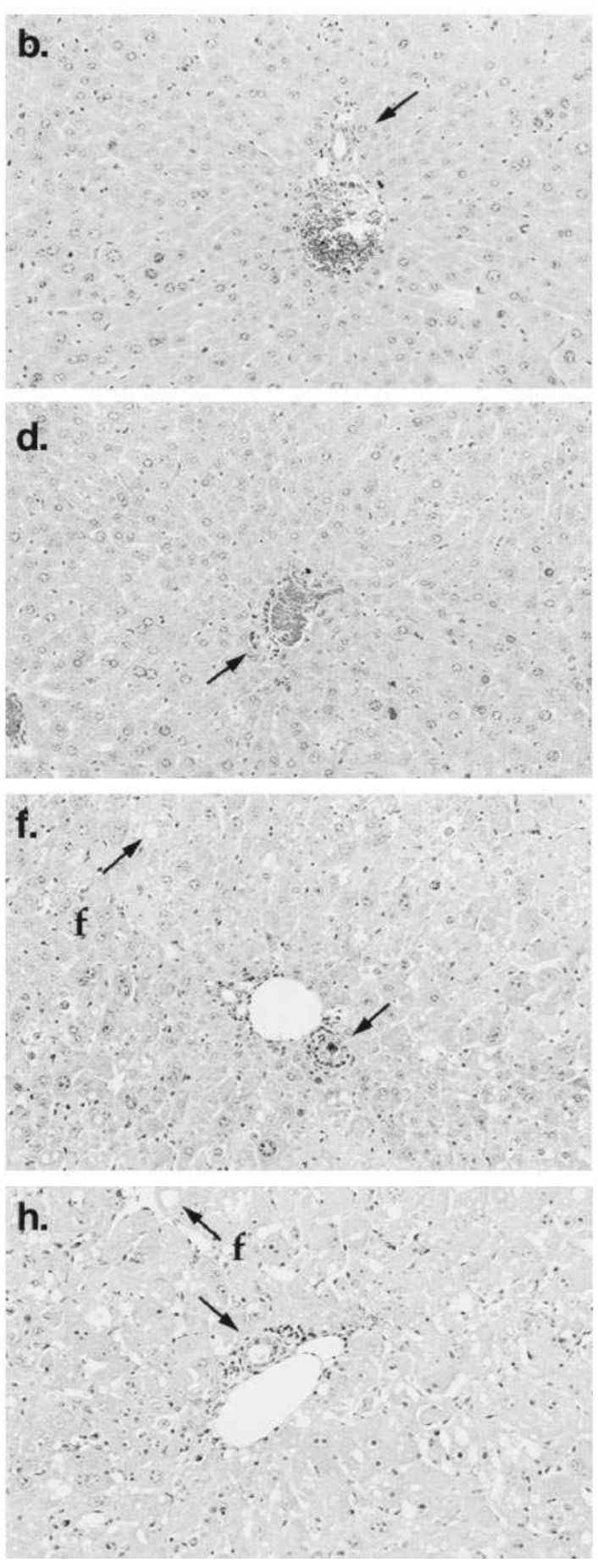

Figure 2. Histopathology of livers from transgenic and nontransgenic mice fed control or griseofulvin diet for $7 \mathrm{~d}$. Nontransgenic (N) or transgenic mice expressing wild-type K18 (TG2) or arg mutant K18 (F22 and F50) were fed a regular or GF-containing diet for 7 d. Livers were then isolated, formalin fixed, paraffin embedded, sectioned and stained with hematoxylin and eosin. Identical magnification was used for all the panels. Arrows indicate portal triad areas. Note bile plug within bile duct in the F22 GF-fed mouse $(f)$; $f$, fat droplets (confirmed by Oil-red O staining, not shown).

All data are expressed as means \pm SD. Statistical significance between means were calculated using Student's $t$ test, nonparametric Wilcoxon method, or logistic regression. Differences in proportions between groups were calculated using Pearson chi-square analysis.
Survival analysis was performed using the Wilcoxon method for determining survival differences in Kaplan-Meier estimates of survival. All statistical analysis was performed using JMP version 3.1 (SAS Intitute Inc., Cary, NC). 


\section{A. GF 17d}
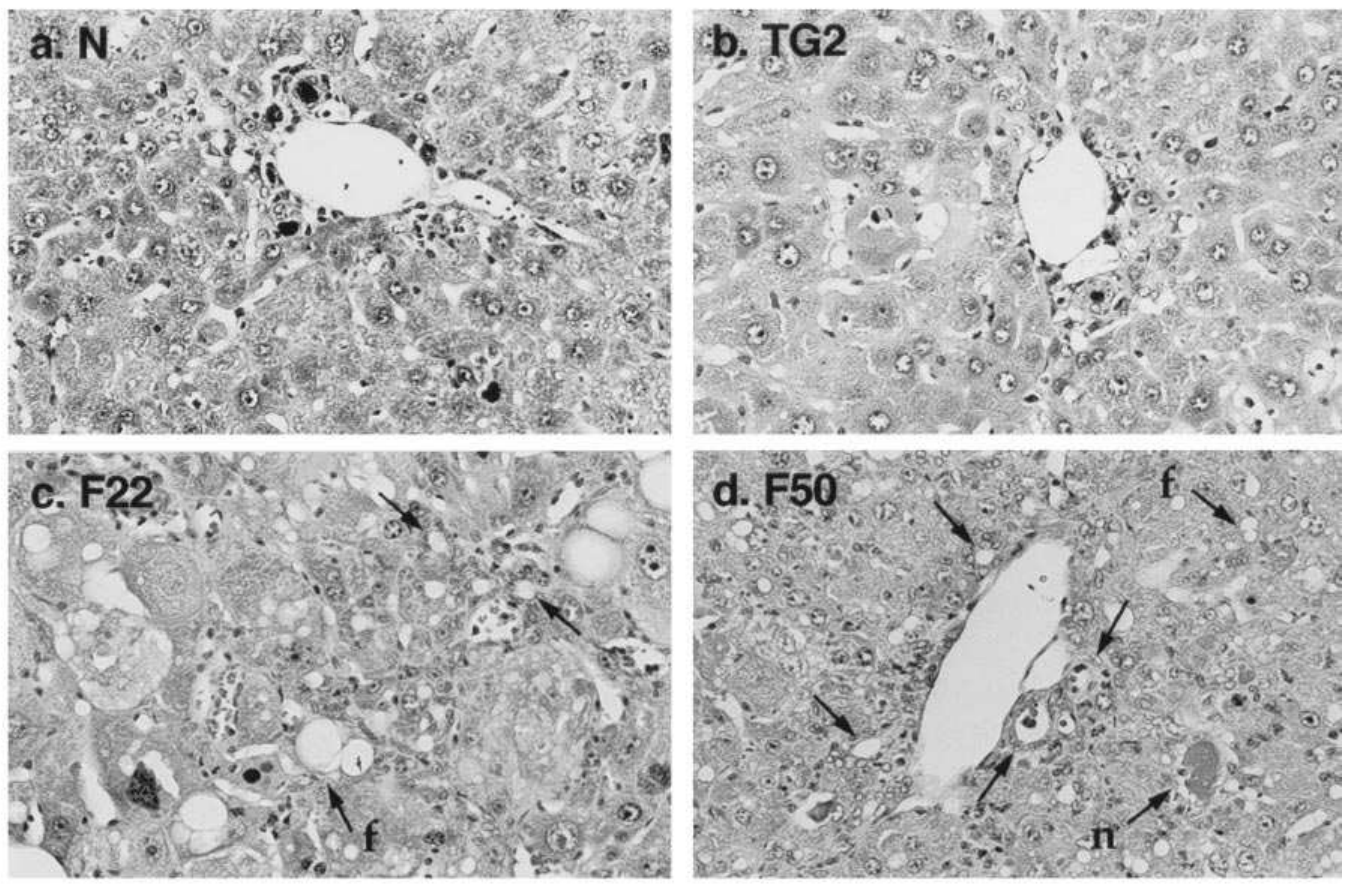

\section{B. Acetaminophen}
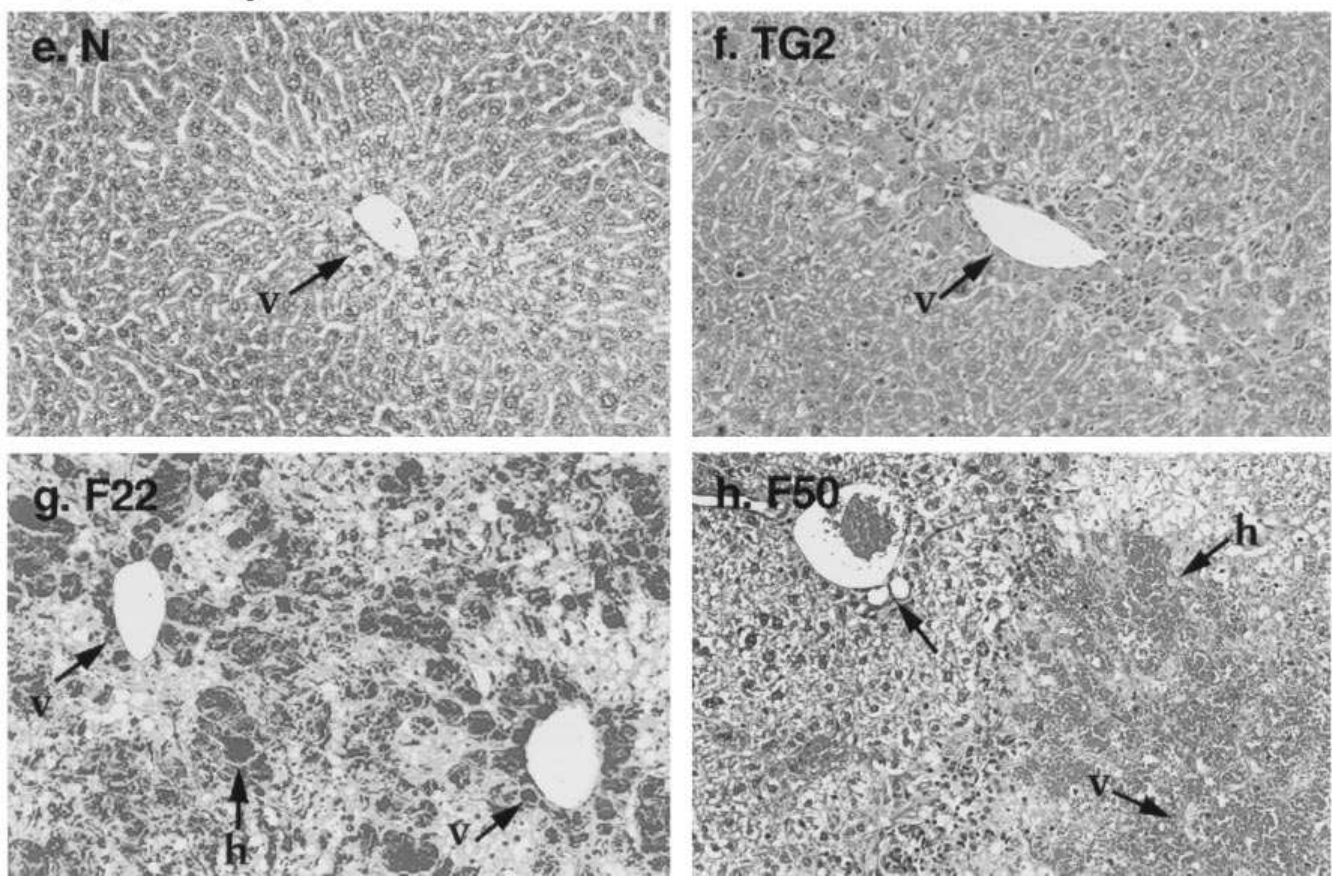

Figure 3. Histopathology of livers from transgenic and nontransgenic mice fed a griseofulvin diet for $17 \mathrm{~d}$ or a one-time dose of acetaminophen. $(A)$ Hematoxylin and eosin stained sections of livers $(a-d)$ were prepared from mice identical to those in Fig. 1. Unlabeled arrows point to bile duct proliferation; $f$, fat droplets; $n$, necrotic hepatocyte. (B) Mice were given acetaminophen by gavage (400 $\mathrm{mg} / \mathrm{Kg}$ ) followed by processing of the livers as done for the GF-fed mice. Identical magnification was used for all the panels. Arrows labeled " $v$ " indicate central vein. Unlabeled arrow in $h$ indicates portal triad. Note the diffuse hemorrhage (h) in $g$, and the significant necrosis and hemorrhage surrounding the central vein in $h$.

Indirect immunofluorescence. Freshly resected liver pieces were immediately frozen in O.C.T. compound (Miles, Elkhart, IN), sectioned then fixed briefly in cold acetone. Sections were blocked with a blocking buffer containing phosphate buffered saline (PBS), $2.5 \%$ bovine serum albumin (BSA) and $2 \%$ normal goat serum $(5 \mathrm{~min})$. They were then incubated with mAb L2A1 (anti-human K18) or with TromaI (anti-mouse K8) ascites diluted (1:40) in PBS with $2.5 \%$ BSA $\left(20 \mathrm{~min}, 22^{\circ} \mathrm{C}\right)$. After washing, sections were blocked with the blocking buffer ( $5 \mathrm{~min}$ ), followed by incubation with Texas red-conjugated goat anti-rat or anti-mouse $\operatorname{IgG}\left(20 \mathrm{~min}, 22^{\circ} \mathrm{C}\right)$ diluted $1: 100$ in blocking buffer with or without $2 \%$ normal mouse serum, respec- tively. After washing in PBS, slides were visualized with a Nikon fluorescent microscope and photos were taken using Kodak Ektachrome 400 color slide film from which black and white pictures were generated.

Biochemical studies. K8/18 were immunoprecipitated from liver fragments that were homogenized in 1\% Empigen BB (Emp) in PBS containing $5 \mathrm{mM}$ EDTA, $25 \mu \mathrm{g} / \mathrm{ml}$ aprotinin, $10 \mu \mathrm{M}$ leupeptin, $10 \mu \mathrm{M}$ pepstatin, $0.1 \mathrm{mM}$ phenylmethyl-sulfonyl fluoride, $0.5 \mu \mathrm{g} / \mathrm{ml}$ okadaic acid, $5 \mathrm{mM}$ Na pyrophosphate, and $50 \mathrm{mM} \mathrm{NaF}$ (buffer A) $(19,39)$. Homogenized samples were allowed to solubilize for $2 \mathrm{~h}$ with rotation $\left(4^{\circ} \mathrm{C}\right)$, followed by centrifugation $(16,000 \mathrm{~g} ; 20 \mathrm{~min})$. Purified L2A1 conjugated to Sepharose beads (39), or 8592 antibody, were 
Table II. Biochemical Serologic Values of Normal and Transgenic Mice after 17 d of Feeding

\begin{tabular}{|c|c|c|c|c|c|}
\hline Type of mice and diet & Glucose & Alkaline phosphatase & Direct bilirubin & AST & ALT \\
\hline \multicolumn{6}{|l|}{ Normal } \\
\hline Control diet & $248 \pm 37$ & $141 \pm 36$ & $0.1 \pm 0.2$ & $87 \pm 43$ & $49 \pm 14$ \\
\hline Griseofulvin diet & $140 \pm 56$ & $2632 \pm 660$ & $0.6 \pm 0.5$ & $3280 \pm 903$ & $6833 \pm 3097$ \\
\hline \multicolumn{6}{|l|}{ TG2 } \\
\hline Control diet & $219 \pm 29$ & $129 \pm 25$ & $0.1 \pm 0.2$ & $112 \pm 4$ & $37 \pm 80$ \\
\hline Griseofulvin diet & $96 \pm 28$ & $2686 \pm 2062$ & $2.9 \pm 2.2$ & $2710 \pm 704$ & $6230 \pm 2698$ \\
\hline \multicolumn{6}{|l|}{$\mathrm{F} 22$} \\
\hline Control diet & $221 \pm 26$ & $160 \pm 38$ & 0 & $123 \pm 14$ & $124 \pm 53$ \\
\hline Griseofulvin diet & $49 \pm 10 *$ & $465 \pm 152^{\ddagger}$ & $9.4 \pm 1.9^{\S}$ & $4933 \pm 1421^{\|}$ & $16447 \pm 3335^{\text {II }}$ \\
\hline \multicolumn{6}{|l|}{ F50 } \\
\hline Control diet & $205 \pm 35$ & $157 \pm 37$ & 0 & $181 \pm 53$ & $129 \pm 29$ \\
\hline Griseofulvin diet & $36 *$ & $438^{\ddagger}$ & $8.8^{\S}$ & $3200^{\|}$ & $10460^{\text {q }}$ \\
\hline
\end{tabular}

Blood samples were collected from the $17 \mathrm{~d}$ group of mice that were described in Table I, then analyzed for glucose (mg/dl); alkaline phosphatase (U/ liter); direct bilirubin (mg/dl); aspartate (AST), and alanine (ALT) aminotransferases (U/liter). Serum testing was also done on blood obtained from the $7 \mathrm{~d}$ mouse groups, and gave a similar trend but less dramatic numbers to those of the $17 \mathrm{~d}$ groups (not shown). For statistical analysis, logistic regression was used to test the effect of type of mice for a given diet. Data of mutant transgenics (F22 + F50) were compared to data from TG2 and normal mice. ${ }^{\ddagger} P=0.009$ for glucose; ${ }^{\ddagger} P=0.025$ for alkaline phosphatase; ${ }^{\circledR} P=0.002$ for bilirubin; ${ }^{\|} P=0.040$ for AST; and ${ }^{\mathbb{\sharp}} P=0.004$ for ALT.

then incubated with the clarified liver lysate $\left(3-12 \mathrm{~h}, 4^{\circ} \mathrm{C}\right)$ followed by washing of the immunoprecipitates then analysis by SDS-PAGE (40). Duplicate K8/18 immunoprecipitates were analyzed by isoelectric focusing using a Mini-PROTEAN II apparatus (BioRad Laboratories, Cambridge, MA) then SDS-PAGE exactly as recommended by the manufacturer. Glycosylation of K8/18 was assessed by in vitro specific labeling of accessible terminal $\mathrm{N}$-acetylglucosamine residues using galactosyltransferase and UDP-[ $\left[{ }^{3} \mathrm{H}\right]$ galactose exactly as described (35).

The amount of liver keratin solubilized by Emp-containing buffer A relative to the total keratin present in liver tissue solubilized by $2 \%$ SDS-containing sample buffer was determined by immunoblotting. For this, equivalent liver fragments (by weight) were homogenized in buffer A or in sample buffer followed by transfer of serial dilutions to an Immobilon-P membrane (Millipore Corp., Bedford, MA) and immunoblotting with anti-keratin antibodies as described (19). Immunoblotting with the 3055 anti-phospho-K18 antibody and quantitation of the increase in phosphorylation of ser52-K18, using standard serial dilutions, was done as described (24).

\section{Results}

Comparison of griseofulvin-induced hepatotoxiciy in transgenic and nontransgenic mice. The hepatotoxic effect of griseofulvin (GF) in mice $(27,28)$ and the formation of cytoplasmic hyalin Mallory bodies $(25,26)$ after chronic administration $(\geq 2 \mathrm{mo})$ of GF are well described. We compared the short term hepatotoxic effect of GF in two founder transgenic mouse lines (F22 and F50) that express an arg mutant human K18, to transgenic mice that express normal human K18 (TG2) and to nontransgenic mice $(\mathrm{N})$ that are the same strain as the transgenic animals. Although the F22 and F50 mice develop a progressive chronic hepatitis as they age (19), we used young mice that have only mild hepatitis. Several parameters were analyzed after 7 and $17 \mathrm{~d}$ of GF administration including mouse mortality, liver gross appearance and histopathology, keratin filament organization, biochemical serologic testing, and liver keratin phosphorylation and glycosylation. As shown in Table I, a statistically significant number of mice from the F22 and F50 groups, exclusively, died after $17 \mathrm{~d}$ of GF administration. Hepatomegaly was noted in all GF-fed mice (Table I), and the mesh-like subcapsular vascular pattern in the $\mathrm{N}$ and TG2 groups became accentuated in association with liver hyperpigmentation (Fig. 1, compare $b$ and $d$ with $a$ and $c$ ) after $17 \mathrm{~d}$ of GF feeding. In contrast, GF-fed F22 and F50 mice showed a relative paucity of the subcapsular vascular mesh-like markings (Fig. 1, $e-h$ ), with scattered patches (e.g., arrows in Fig. 1, $f$ ) that correspond to foci of hemorrhage and necrosis (confirmed histologically, not shown but see Fig. 3).

Livers of 7-d GF-fed N and TG2 mice showed similar histologic changes, with an intact architecture and mild enlargement of hepatocyte nuclei (Fig. 2, compare $b$ and $d$ with $a$ and c). In contrast, 7-d GF-fed F22 and F50 mice showed disarray of liver architecture with hepatocyte and bile duct cell enlargement that was not seen in control-fed F22 and F50 mice (Fig. 2, compare $f$ and $h$ with $e$ and $g$ ). These changes in the livers from F22 and F50 mice became significantly more dramatic after $17 \mathrm{~d}$ of GF feeding (Fig. $3 A, a-d$ ). Although livers of all GF-fed mice were injured, changes of disorganization, necrosis, fatty change, bile duct swelling and cell proliferation are clearly more evident in the F22 and F50 mice than the N and TG2 mice (Fig. $3 A, a-d$ ). Mallory bodies were not seen in any of the mouse lines after the $17 \mathrm{~d}$ GF feeding (not shown). The histologic changes were paralleled by a significant decrease in serum glucose, and significant increases in serum ALT, AST

Table III. Effect of Acetaminophen on Survival of Normal and Transgenic Mice

\begin{tabular}{ccccc}
\hline Category & Normal & TG2 & F22 & F50 \\
\hline Dead/Total & $1 / 11$ & $1 / 11$ & $6 / 11$ & $5 / 11$
\end{tabular}

11 (sex matched, two months old) mice from each group were given acetaminophen $(400 \mathrm{mg} / \mathrm{kg})$ by gavage, followed by observation for $72 \mathrm{~h}$. All the mice that died, independent of the group, did so within the first $36 \mathrm{~h}$ after acetaminophen administration. Chi-square $=8.84, P<$ 0.003 for the sum of mutant transgenic (F22 + F50) mice compared to TG2 plus normal mice, in terms of survival. 

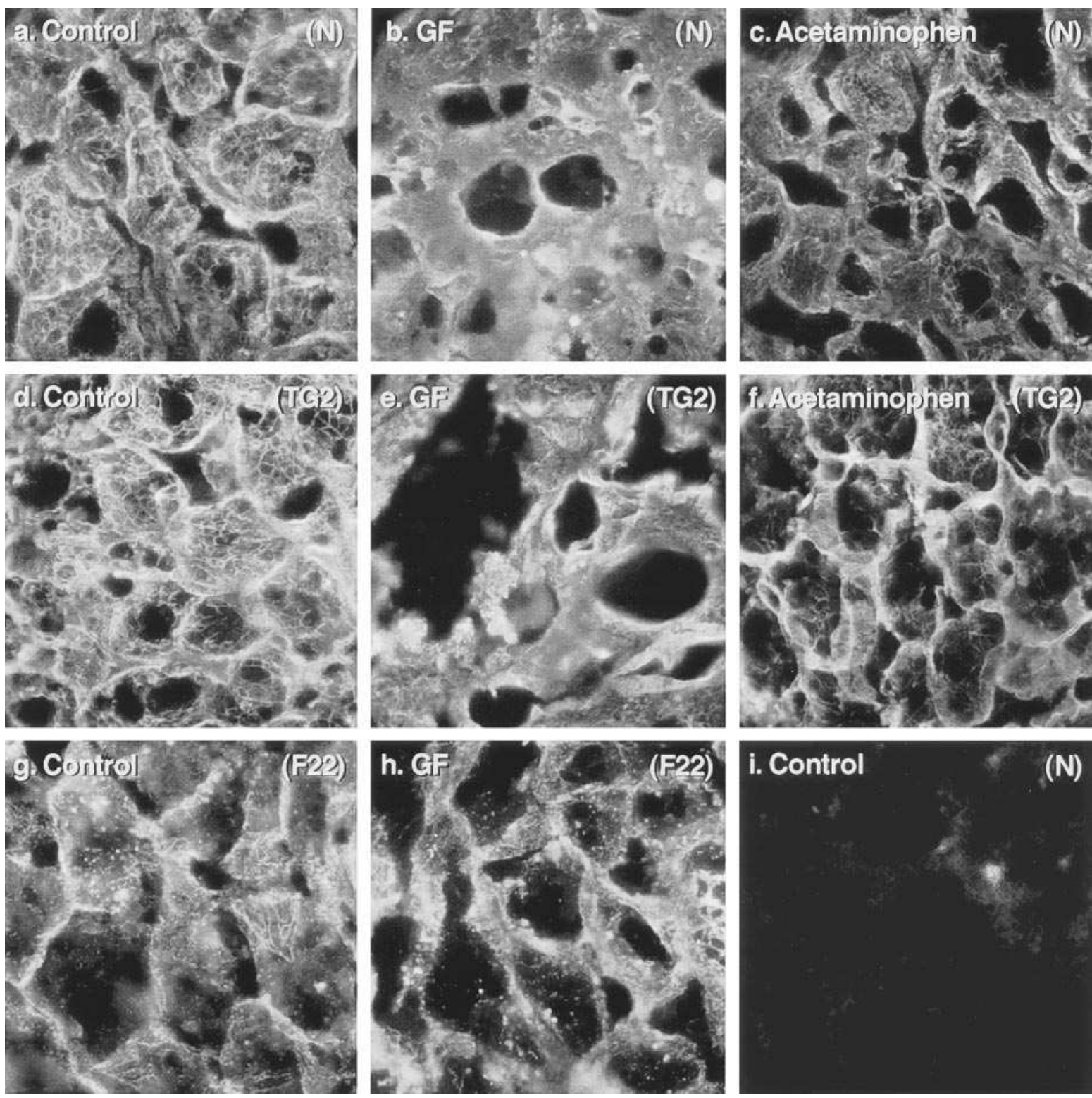

Figure 4. Immunofluorescence staining of K8/18 in livers isolated from mice fed GF or acetaminophen. Nontransgenic (N), TG2 or F22 mice were fed a control diet, a $1.25 \% \mathrm{wt} / \mathrm{wt} \mathrm{GF-containing} \mathrm{diet,} \mathrm{or} \mathrm{were} \mathrm{given} 400 \mathrm{mg} / \mathrm{Kg}$ acetaminophen by gavage. Livers were then isolated after $17 \mathrm{~d}$ of GF feeding, or after $3 \mathrm{~d}(c)$ and $2 \mathrm{~d}(f)$ of acetaminophen admininstration, then stained using anti-mouse K8 mAb Troma I $(a-c)$ or antihuman K18 mAb L2A1 $(d-i)$ as described in Methods. $i$ represents background staining, and shows lack of staining with mAb L2A1 and Texas red conjugated goat anti-mouse antibody of a liver section isolated from $\mathrm{N}$ mice that were fed a control diet. Staining of liver sections only with the second stage antibody, without a primary antibody, resulted in a background staining pattern similar to that in $i$ (not shown).

and bilirubin levels (Table II). Interestingly, F22 and F50 mice were not able to mount an increase in their alkaline phosphatase levels to the extent noted in TG2 and $\mathrm{N}$ mice (Table II). The significance of this difference in alkaline phosphatase is unclear but may reflect an inherent difference in synthesis, transport or secretion in mice expressing the arg mutant K18.

Comparison of acetaminophen-induced hepatotoxicity in transgenic and nontransgenic mice. We examined the effect of acute acetaminophen-induced hepatotoxicity, another well recognized hepatotoxin, in addition to the GF-induced chronic hepatotoxicity described above. We chose a gavage dose of $400 \mathrm{mg} / \mathrm{Kg}$ that was in the $300-500 \mathrm{mg} / \mathrm{Kg}$ range previously described in acetaminophen-induced hepatotoxicity in C57B16 and $\mathrm{C} 3 \mathrm{H}$ mice (36), and which in preliminary experiments was minimally lethal in FVB/ $\mathrm{N}$ nontransgenic mice (not shown). Mice were analyzed in a manner similar to that described for the GF experiments, $72 \mathrm{~h}$ after acetaminophen gavage. As shown in Table III, mortality was significantly greater in F22 and F50 mice than in TG2 and N mice. This was also supported by the dramatic difference noted after histologic analysis of the livers (Fig. $3 B, e-h$ ). Most of the histologic changes, as manifested by necrosis and hemorrhage, occured in areas surrounding central veins. The observed effects were not due to the gavage per se, since no mortality or hemorrhage were noted in eleven F22 mice that were gavaged with $0.4 \mathrm{ml}$ of water (not shown). No significant differences were noted in ALT, AST, 

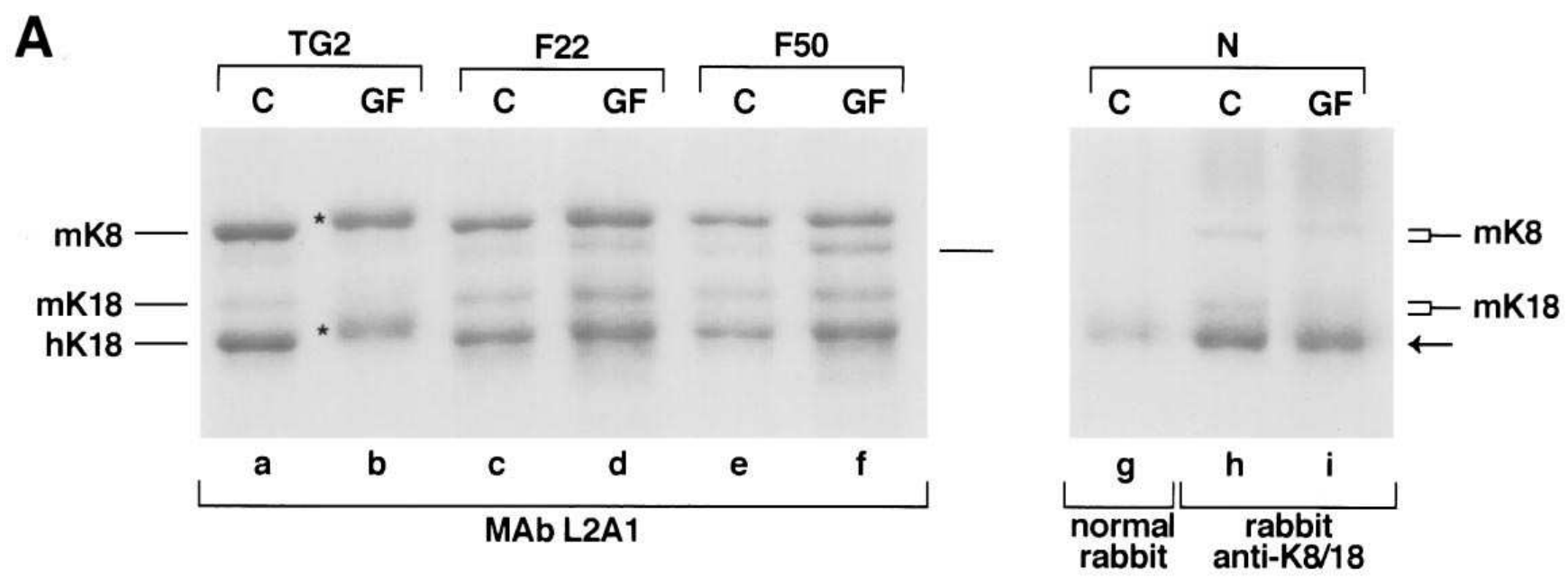

B
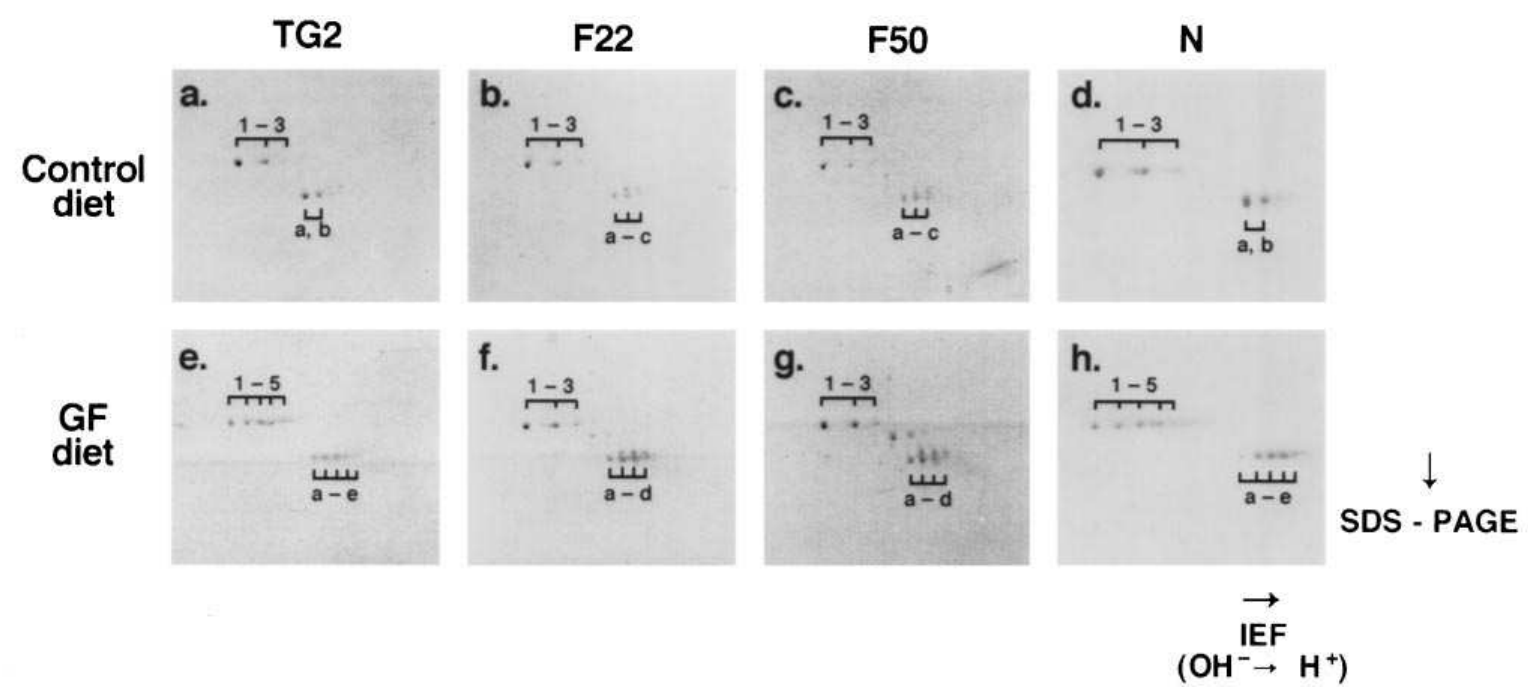

Figure 5. Biochemical analysis of liver keratins isolated from transgenic and nontransgenic mice fed control or griseofulvin diets for $17 \mathrm{~d}$. $(A)$ Livers were isolated from mice fed control or $1.25 \%$ (wt/wt) GF-containing diet for $17 \mathrm{~d}$. Livers were then solubilized in $1 \%$ Emp followed by immunoprecipitation of K8/18 from the detergent solubilized fraction as described in Methods. mAb L2A1 was used to immunoprecipitate K8/ 18 from transgenic mouse livers (lanes $a-f$ ) and a rabbit anti-K8/18 was used to immunopurify keratins from normal mouse livers (lanes $h$ and $i$ ). A normal rabbit antibody was used as a control for normal mouse liver immunoprecipitation (lane $g$ ). Precipitates were analyzed by SDS-PAGE followed by Coomassie staining. Bands corresponding to endogenous mouse (m) K8 and K18 and human (h) transgenic K18 are shown. Bar to the right of lane $f$ corresponds to a degradation product of K8. Note the slower migration of liver K8 and K18 isolated from GF-fed TG2 mice (lane $b$, bands highlighted by asterisks) or from GF-fed N mice (lane $i$ ) Immunoprecipitation using normal mouse ascites conjugated to Sepharose results in a blank lane after SDS-PAGE (not shown). Nonspecific rabbit antibody heavy chain band, indicated by an arrow (lanes $g-i$ ), is released since the rabbit antibodies used were not coupled to Sepharose. C, control diet, $G F$ griseofulvin. (B) Immunoprecipitates of K8/18 (duplicates of those in $A$ ) were analyzed by isoelectric focusing (IEF) (horizontal direction) then SDS-PAGE (vertical direction) followed by Coomassie staining. Bracketed numbers $(\mathrm{mK} 8)$ and letters $(\mathrm{m}, \mathrm{hK} 18)$ represent the major Coomassie stained isoforms.

bilirubin, glucose, and alkaline phosphatase between surviving mice $72 \mathrm{~h}$ after acetaminophen administration which is explained by their rapid near normalization in surviving mice (not shown).

Effect of $G F$ and acetaminophen on keratin filament assembly. We examined the effect of GF and acetaminophen on hepatocyte keratin filament assembly in the transgenic (TG2, F22, F50) and nontransgenic (N) mice. As shown in Fig. 4, GF feeding of $\mathrm{N}$ and TG2 mice for $17 \mathrm{~d}$ resulted in significant alteration in the pattern of keratin staining, from an extended filamentous array $(a$ and $d$ ) to a hazy disorganized pattern with few short filaments and scattered dots $(b$ and $e$ ). The staining patterns for K8/18 in livers of $\mathrm{N}$ and TG2 mice after $7 \mathrm{~d}$ of GF feeding was similar but less dramatic than after $17 \mathrm{~d}$ of feeding (not shown). The staining patterns for K8/18 in F22 (Fig. 4, $g$ and $h$ ) and F50 (not shown) were similar, with disruption of keratin filaments in mice fed a control diet because of the K18 mutation as described previously (19) and minimal change after GF feeding. The staining patterns of K8/18 in livers from transgenic mice using mAb L2A1 (Fig. $4, d-h$ ) or using mAb Troma I were similar (not shown), and background nonspecific staining (Fig. $4 i$ ) was negligible and without cross-reactivity of mAb L2A1 with mouse K8/18.

The staining patterns for liver keratins in the $\mathrm{N}$ and TG2 


\section{A Coomassie stain}

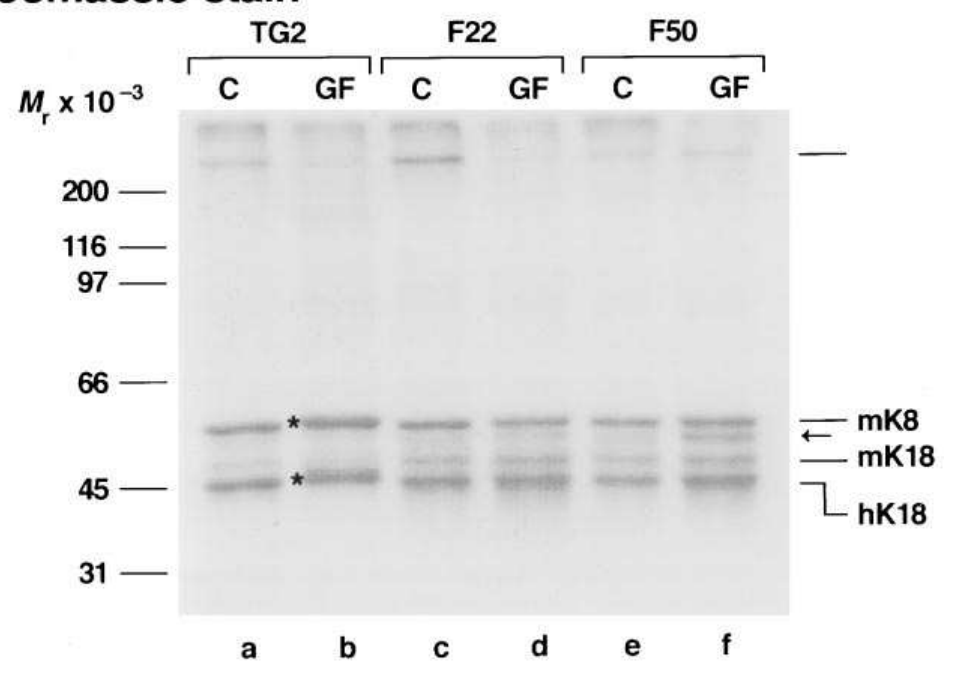

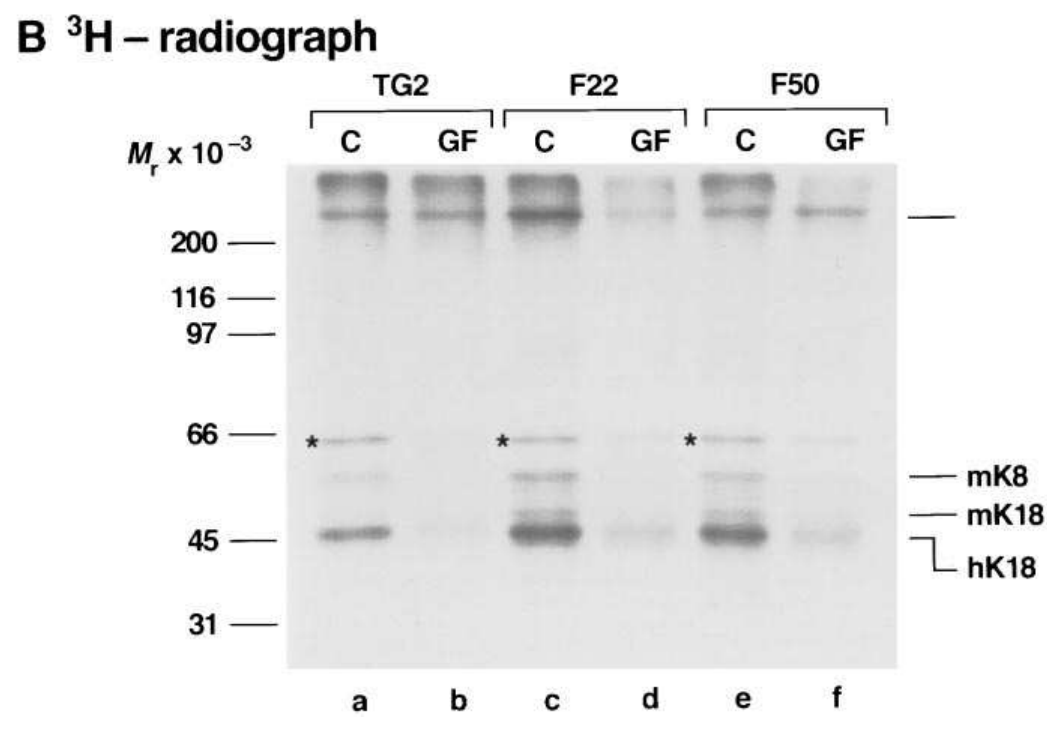

Figure 6. Analysis of keratin glycosylation in livers isolated from transgenic mice fed control or griseofulvin diets for $17 \mathrm{~d}$. Immunoprecipitates of K8/18 were obtained from mouse livers as done in Figure 5 followed by galactosylation using UDP- $\left[{ }^{3} \mathrm{H}\right]$ galactose and galactosyltransferase, which label accessible terminal GlcNAc moieties, as described in Methods. After washing off unbound radioactivity, immunoprecipitates were analyzed by SDS-PAGE followed by Coomassie staining $(A)$ then fluorography $(B)$. Asterisks in panel A (lane b) indicate highly phosphorylated K8 and K18. Arrow in panel A indicates a degradation product of $\mathrm{mK} 8$. The band in $B$ indicated by an asterisk $\left(M_{\mathrm{r}} \sim 64 \mathrm{kD}\right)$ is not seen by Coomassie staining in panel A or in non-specific antibody background immunoprecipitates (not shown), and its identity is not known. The identity of the band above the $200-\mathrm{kD}$ marker (indicated by a bar in $A$ and $B$ ) is not known. $C$, control diet; GF, griseofulvin diet. acetaminophen mouse group were somewhat different than those observed after GF administration. The effect on filament staining $1 \mathrm{~d}$ after acetaminophen gavage was mild (not shown). However, changes in keratin filaments became more evident $2 \mathrm{~d}$ (Fig. $4 \mathrm{f}$ ) or $3 \mathrm{~d}$ (Fig. $4 \mathrm{c}$ ) after acetaminophen gavage, with a disorganized and less extended filamentous pattern, and some loss of cytoplasmic staining. This staining pattern was heterogeneous, with areas exhibiting a normal filamentous staining pattern and other areas of necrosis (not shown). As noted after GF feeding of F22 and F50 mice, the staining pattern of K8/18 was not dramatically different in livers of surviving F22 and F50 mice before or after acetaminophen gavage (not shown).

Effect of GF on keratin phosphorylation and glycosylation. We compared the phosphorylation and glycosylation states of hepatic K8/18 in mice with or without hepatotoxin pre-exposure. This analysis was prompted by several previous observations. For example, basal phosphorylation and glycosylation of $\mathrm{K} 8 / 18$ is elevated in transgenic mice that express the arg mutant K18 as compared with mice that express normal K18 (19). In addition, keratin phosphorylation increased in normal mice after 3.5-8 mo of chronic GF feeding $(29,30)$. As shown in Fig. 5 A, immunoprecipitation of K8/18 from Emp detergent-solubilized livers showed that K8 and K18 migrate slower, upon one dimensional SDS-PAGE, after isolation from GF-fed normal and TG2 mice as compared with keratins isolated from the corresponding control fed mice (compare lanes $b$ with $a$; and lanes $i$ with $h$ ). In contrast, K8/18 isolated from control or GF fed F22 or F50 mice showed similar migrations (Fig. $5 A$, lanes $c-f$ ).

Support for earlier findings that GF feeding in normal mice results in hyperphosphorylation of K8/18 $(29,30)$ was obtained by two-dimensional gel analysis. As shown in Fig. $5 \mathrm{~B}$, several new isoforms of $\mathrm{K} 8$ and $\mathrm{K} 18$, that are isolated from $\mathrm{N}$ and TG2 mice after GF feeding, are evident. In the case of keratins isolated from GF-fed F22 and F50 mouse livers, the shift in K8 and K18 to more acidic (i.e., hyperphosphorylated) isoforms was not as prominent as for keratins isolated from N and TG2 livers (Fig. $5 \mathrm{~B}$ ). This indicates that significant hyperphosphorylation of K8/18 occurs after chronic GF feeding of normal mice or transgenic mice that overexpress normal human $\mathrm{K} 18$, but much less so in mice that express mutant K18. The phos- 


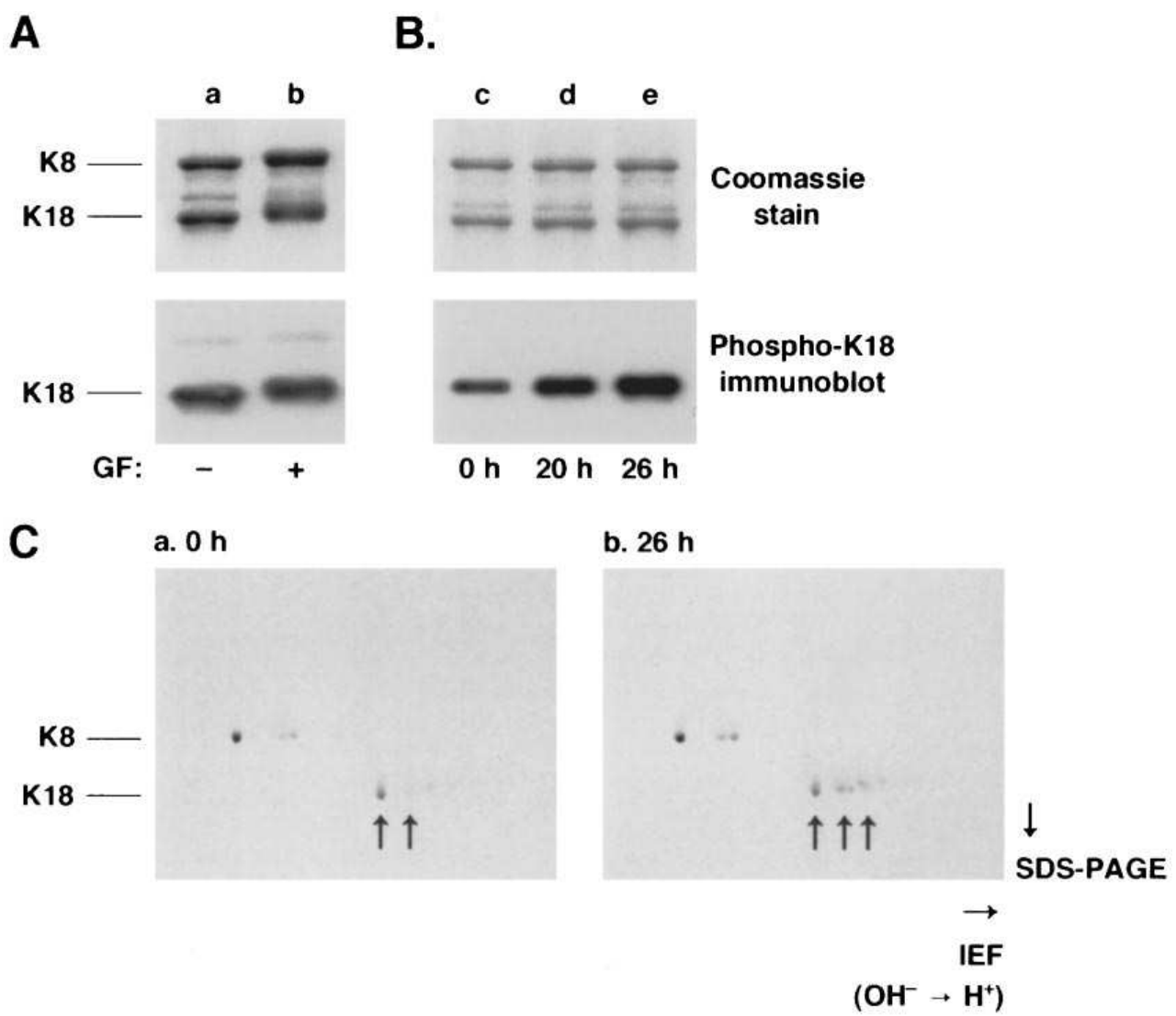

A

oomassie stain

Phospho-K18 immunoblot

$\left(\mathrm{OH}^{-} \rightarrow \mathrm{H}^{+}\right)$
Figure 7. Comparison of K18 ser52 phosphorylation in livers isolated from $\mathrm{GF}$ fed or partial hepatectomized TG2 mice. $(A)$ $\mathrm{K} 8 / 18$ immunoprecipitates were obtained from control diet or $17 \mathrm{~d}$ GF fed TG2 mouse livers. (B) A $65 \%$ partial hepatectomy was performed on TG2 mice as described in Methods. The removed livers ( $0 \mathrm{~h}$ time-point) were snap frozen in liquid nitrogen, and at $20 \mathrm{~h}$ and $26 \mathrm{~h}$ after hepatectomy mice were euthanized followed by removal of the regenerated livers. K8/18 were then immunoprecipitated from the initially removed $(0 \mathrm{~h})$ and regenerated $(20 \mathrm{~h}, 26 \mathrm{~h})$ livers followed by SDS-PAGE then Coomassie staining. Duplicate immunoprecipitates to those shown by Coomassie staining were also analyzed by immunoblotting using rabbit antibody 3055 which specifically recognizes phospho-ser52K18. (C) K8/18 immunoprecipitates, isolated from the $0 \mathrm{~h}$ and $26 \mathrm{~h}$ livers were analyzed by IEF (horizontal direction) then SDSPAGE (vertical direction) followed by Coomassie staining. Small arrows highlight major K18 isoforms. phorylation increase in $\mathrm{K} 8 / 18$, isolated from normal and TG2 mouse livers, was noted only in the Emp solubilized keratin fraction $(\sim 70 \%$ of the total liver keratin pool) but not in the residual post-Emp keratin fraction (not shown).

We also compared keratin glycosylation in TG2, F22, and F50 mice that were fed control or GF-containing diet. The glycosylation of $\mathrm{K} 8 / 18$ consists of O-linked single N-acetylglucosamines (35), and in the case of K18 three major glycosylation sites have been identified (ser-29, 30 and 48; reference 41). As shown in Fig. 6, K8/18 glycosylation decreased in all GF fed mice as determined by in vitro galactosylation of in vivo modified and accessible $\mathrm{N}$-acetylglucosamines. This dissociation between keratin glycosylation and phosphorylation is different to other examples where increased keratin phosphorylation/glycosylation occured in concert as in the case of heat stress or virus infection of tissue cultured cells (21) or mitotic arrest $(22,23)$. The glycosylation of K8/18 in livers of F22 and F50 mice fed a control diet was higher than that in similarly fed TG2 mice as described previously (19).

Increased phosphorylation of K18 in GF-fed TG2 mice is different to mitosis-associated K18 hyperphosphorylation in partial hepatectomized mice. The increase of K8/18 phosphorylation in TG2 mouse livers after GF-feeding raises the possibility that it may be related to a compensatory hyperproliferative response. This was addressed by contrasting the phosphorylation of $\mathrm{K} 18$, in GF versus control diet fed mice, to the phosphorylation of K18 in resected versus post-resection regenerated livers. In the latter case, liver generation and the associated increase in cell proliferation are well described (reviewed in 42) with early studies done in rats (43) and mice (44). K18 phosphorylation on ser52, a major K18 phosphorylation site (45), was examined by immunoblotting using antibody 3055 which specifically recognizes phospho-ser52-K18 (24). As shown in Fig. 7, the increase in K18 phosphorylation after GF feeding does not involve ser52 $(A)$ but, in contrast, K18 hyperphosphorylation after liver resection does involve ser52 $(B)$. The mean increase in K18 ser52 phosphorylation $26 \mathrm{~h}$ after partial hepatectomy was $2.4 \pm 0.4(n=2)$. Liver regenerative activity was obvious on visible inspection and by PCNA staining (not shown). The overall hyperphosphorylation of K18 after partial hepatectomy was confirmed using two-dimensional gel analysis (Fig. 7 $C$ ), which showed an increase in the intensity of the acidic (i.e., hyperphosphorylated) Coomassie stained isoforms of K18.

\section{Discussion}

The major findings of this study are: (a) Transgenic mice that express human K18 that is mutated at a single highly conserved arginine are significantly more susceptible to griseofulvin or acetaminophen induced hepatotoxicity than transgenic mice that express normal human K18 at levels that are near or higher than the mutant protein levels. The increased susceptibility of F22 and F50 mice to hepatotoxicity, as compared with normal and TG2 mice, was manifested by statistically significant differences in lethality (Tables I and III), histology (Figs. 2 and 3), and serologic tests (Table II). (2) Despite higher basal phosphorylation of keratins in livers that express mutant $\mathrm{K} 18$, these hepatocytes are unable to manifest the dramatic 
$\mathrm{K} 8 / 18$ hyperphosphorylation response that is seen after GF feeding of nontransgenic mice or of mice that express normal human K18 (Fig. 5). (3) Hyperphosphorylation of K18 in GFfed TG2 mice does not appear to be related to a hyperproliferative reponse as seen during liver regeneration (Fig. 7). (4) Griseofulvin administration results in decreased glycosylation of hepatic K8/18, independent of whether the hepatocytes express normal or mutant K18 (Fig. 6).

Susceptibility of transgenic mice that express mutant K18 to drug induced hepatotoxicity. Transgenic mice that express the dominant negative arg mutant human K18 develop chronic hepatitis which led us to hypothesize that some cases of human idiopathic hepatitis may be caused by mutations in human K18 (19). Identification of K18 mutations in human disease(s) may be predicted given that mutations in 11 other keratins have already been described in tissue-specific human diseases (4-11). Our study herein brings to light the additional hypothesis that mutations in K18 may, in some cases, predispose to human acute or chronic drug induced hepatotoxicity. Although the mutant K18 mice that we studied do have underlying chronic hepatitis, and as such it may be possible that their liver reserve is limited, it is likely that their predisposition to liver injury is more related to the mutation-induced keratin filament disruption than to the underlying chronic liver disease. In support of this, TG2 mice that express normal human K18 have normal keratin filament organization $(19,20)$ and show a similar susceptibility to liver toxicity as normal nontransgenic mice. In addition, we used young mice for our study, where the degree of chronic hepatitis is still mild (19).

Based on the well described mutations in epidermal keratins, the location of a particular mutation appears to correlate with the severity of the skin disease phenotype. For example, mutation of the highly conserved arg 125 in K14 (that corresponds to arg 89 in K18) is associated with the Dowling-Meara form of EBS (4-7), which is the most severe form of that disease. However, mutations in areas that are less critical for filament assembly are found in the mildest form of EBS namely, the Weber-Cockayne type (46). If mutations in K18 are proven to be associated with human drug induced hepatotoxicity, then a similar situation may occur in K18 in that the location of the mutation could account for the severity of the predisposition to drug-induced liver damage.

The mechanism of increased liver injury in the transgenic mice that express mutant K18 remains to be investigated. Although hepatocytes in mice expressing a dominant negative K18 mutant are fragile (19), it is unclear what factor(s) account for this increased fragility except for the association with abnormal filament organization. Environmental contributions to disease phenotype, as exemplified by the exacerbating effect of heat in patients with EBS, may be at least partially accounted for by the effect of the environmental factor on filament organization (47). Although the potential for K18 mutations to cause human disease remains to be investigated, it is also possible that $\mathrm{K} 8 / 18$ mutations may not directly cause disease but may predispose to it, as for example, a susceptibility to liver disease upon exposure to an environmental factor such as a virus or hepatotoxin. Altered filament organization and increased cell fragility may be the major factors involved in lowering the threshold for cell necrosis and toxicity, but other potential mechanisms may directly or indirectly be involved. For example, a dominant-negative K18 mutation could render hepatocytes less able to handle oxidative stress. This is particu- larly relevant given that hepatocytes are the major drug-metabolizing factory in the body. For example, detoxification of acetaminophen, particularly when given in high doses, involves glutathione, which when depleted results in accumulation of the electrophilic and toxic compound N-acetyl-p-benzoquinoneimine $(34,48)$. Similarly, GF feeding of mice for $12 \mathrm{~d}$ decreased cytochrome P-450 content and also elevated fatty acid desaturation activity, thereby suggesting alterations in lipid peroxidation by-products $(49,50)$. In addition, phosphorylation of keratins may contribute by providing a protective mechanism as discussed below.

Keratin glycosylation and phosphorylation in mice expressing normal or mutant K18. Another major finding of this work was that $\mathrm{K} 8 / 18$ become significantly hyperphosphorylated after GF feeding in normal and TG2 mice, but surprisingly not to the same extent in F22 and F50 mice. The K8/18 hyperphosphorylation is dramatic and results in a migration shift of $\mathrm{K} 8$ and K18 on one-dimensional gels (Figs. 5-7) and generation of new isoelectric forms on two dimensional gel analysis (Fig. 5). Although shifts of mouse liver K8/18 on one dimensional gels have not been reported previously, similar changes in $\mathrm{K} 8 / 18$ phosphorylation upon two-dimensional gel analysis were noted in $\mathrm{C} 3 \mathrm{H}$ or swiss albino mice that were fed $2.5 \% \mathrm{GF}$ (wt/ wt) for 8 or $3.5 \mathrm{mo}$, respectively $(29,30)$. Hence, GF induced hyperphosphorylation of keratins in normal mice, or in mice that overexpress wild type human K18, appears to be a general phenomenon that begins as early as 17 days after GF feeding, irrespective of the mouse strain.

Hyperphosphorylation of normal keratins is emerging as a common theme that is associated with several in vitro stress models (reviewed in 51), such as heat stress or infection of cultured colonic epithelial cells with rotavirus (21), or mitotic arrest $(22,23)$. In the case of heat stress, hyperphosphorylation begins at a stage before cell damage becomes irreversible (21). These data, coupled with the toxicity stress model in this study, raise the question of whether keratin hyperphosphorylation is an important component of normal cellular protective responses against injury. Any survival advantage that may be imparted by stress-induced keratin hyperphosphorylation can be assessed once the specific newly phosphorylated sites are identified. To that end, the observed hyperphosphorylation of human K18 in TG2 GF-fed mice does not involve ser52 (Fig. 7). This contrasts with the 3-4-fold increase in K18 phosphorylation during the $\mathrm{S}$ and $\mathrm{G} 2 / \mathrm{M}$ phases of the cell cycle in cultured colonic HT29 cells $(23,24)$ and the 2.4 -fold increase $26 \mathrm{~h}$ after partial hepatectomy and subsequent liver regeneration (Fig. 7). Taken together, this suggests that the observed K8 and K18 hyperphosphorylation may occur at unique "nonconventional" sites. Further support for the uniqueness of the GFinduced phosphorylation sites is related to the observed shift of K8 and K18 on one-dimensional gels. This migration shift was not detected during the S/G2/M phases of the cell cycle when keratins become significantly hyperphosphorylated (23, 24), but was noted in K8 (with formation of a distinct hyperphosphorylated species) after heat stress (21) or mitotic arrest (22) and was coupled with generation of unique phosphopeptides.

With regard to keratin glycosylation, little is known regarding the functional significance of this modification (reviewed in references 52, 53), despite its dynamic nature $(22,35)$. Several in vitro systems that are associated with keratin hyperphosphorylation show either a parallel hyperglycosylation, as after mitotic arrest or heat stress $(21,22)$, or no change in glycosyla- 
tion as noted upon virus infection or normal progression through the cell cycle $(21,23)$. The decrease in hepatocyte K8/ 18 glycosylation after GF feeding represents the first example of opposite alterations in keratin phosphorylation and glycosylation. The mechanism(s) accounting for this effect on K8/18 glycosylation remain(s) to be investigated. Potential explanations include the observed increase in K8/18 phosphorylation at "nonconventional" sites that could block normally glycosylated ser/thr's (53), or a GF-induced keratin conformational change that renders the terminal O-GlcNAc's of K8/18 inaccessible during the in vitro galactosylation reaction.

\section{Acknowledgments}

We are very grateful to Vicky Domingo and Romola L. Breckenridge for preparing the manuscript, Kris Morrow for preparing the figures, Marta Raygoza for animal breeding and care, Janet R. Maynard and Ron Van Groningen for serum testing, and Phuoc Vo for assistance with gavaging.

This work was supported by Veterans Administration Merit and Career Development Awards (S.A. Michie and M.B. Omary), NIH grant DK-47918 (M.B. Omary), and Digestive Disease Center grant DK-38707. Nam-On Ku is a recipient of an American Heart Association California Affiliate Postdoctoral Fellowship. Roy M. Soetikno is a recipient of an American Digestive Health Foundation Outcomes Research Training Award.

\section{References}

1. Moll, R., W.W. Franke, D.L. Schiller, B. Geiger, and R. Krepler. 1982. The catalog of human cytokeratins: patterns of expression in normal epithelia, tumors and cultured cells. Cell. 31:11-24.

2. Steinert, P.M., and D.R. Roop. 1988. Molecular and cellular biology of intermediate filaments. Ann. Rev. Biochem. 57:593-625.

3. Fuchs, E., and Weber, K. 1994. Intermediate filaments: structure, dynamics, function and disease. Annu. Rev. Biochem. 63:345-382.

4. Fuchs, E., and P.A. Coulombe. 1992. Of mice and men: genetic skin diseases of keratin. Cell. 69:899-902.

5. Steinert, P.M., and S.J. Bale. 1993. Genetic skin diseases caused by mutations in keratin intermediate filaments. Trends Genet. 9:280-284.

6. Fuchs, E., Y-M. Chan, A.S. Paller, and Q-C. Yu. 1994. Cracks in the foundation: keratin filaments and genetic disease. Trends Cell Biol. 4:321-326.

7. McLean, W.H.I., and E.B. Lane. 1995. Intermediate filaments in disease. Curr. Opin. Cell Biol. 7:118-125.

8. McLean, W.H.I., E.L. Rugg, D.P. Lunny, S.M. Morley, E.B. Lane, O. Swensson, P.J.C. Dopping-Hepenstal, W.A.D. Griffiths, R.A.J. Eady, C. Higgins, H.A. Navsaria, I.M. Leigh, T. Strachan, L. Kunkeler, and C.S. Munro. 1995. Keratin 16 and keratin 17 mutations cause pachyonychia congenita. $\mathrm{Na}$ ture Genet. 9:273-278.

9. Bowden, P.E., J.L. Haley, A. Kansky, J.A. Rothnagel, D.O. Jones, and R.J. Turner. 1995. Mutation of a type II keratin gene (K6a) in pachyonychia congenita. Nature Genet. 10:363-365.

10. Rugg, E.L., W.H.I. McLean, W.E. Allison, D.P. Lunny, R.I. Macleod, D.J. Felix, E.B. Lane, and C.S. Munro. 1995. A mutation in the mucosal keratin K4 is associated with oral white sponge nevus. Nature Genet. 11:450-452.

11. Richard, G., V. De Laurenzi, B. Didona, S.J. Bale, and J.G. Compton. 1995. Keratin 13 point mutation underlies the hereditary mucosal epithelia disorder white sponge nevus. Nature Genet. 11:453-455.

12. Figlewicz, D.A., A. Krizus, M.G. Martinoli, V. Meininger, M. Dib, G.A. Rouleau, and J.-P. Julien. 1994. Variants of the heavy neurofilament subunit are associated with the development of amyotrophic lateral sclerrosis. Hum. Mol. Genet. 3:1757-1761.

13. Vassar, R., P.A. Coulombe, L. Degenstein, K. Albers, and E. Fuchs. 1991. Mutant keratin expression in transgenic mice causes marked abnormalities resembling a human genetic skin disease. Cell. 64:365-380.

14. Coulombe, P.A., M.E. Hutton, A. Letai, A. Hebert, A.S. Paller, and E. Fuchs. 1991. Point mutations in human keratin 14 genes of epidermolysis bullosa simplex patients: Genetic and functional analysis. Cell. 66:1301-1311.

15. Baribault, H., R. Price, K. Miyai, and R.G. Oshima. 1993. Mid-gestational lethality in mice lacking keratin 8. Genes \& Dev. 7:1191-1202.

16. Baribault, H., J. Penner, R.V. Iozzo, and M. Wilson-Heiner. 1994. Colorectal hyperplasia and inflammation in keratin 8-deficient $\mathrm{FVB} / \mathrm{N}$ mice. Genes \& Dev. 8:2964-2973.

17. Blessing, M., U. Ruther, and W.W. Franke. 1993. Ectopic synthesis of epidermal cytokeratins in pancreatic islet cells of transgenic mice interferes with cytoskeletal order and insulin production. J. Cell Biol. 120:743-755.

18. Albers, K.M., F.E. Davis, T.N. Perrone, E.Y. Lee, Y. Liu, and M. Vore. 1995. Expression of an epidermal keratin protein in liver of transgenic mice causes structural and functional abnormalities. J. Cell Biol. 128:157-169.

19. Ku, N-O., S. Michie, R.G. Oshima, and M.B. Omary. 1995. Chronic hepatitis, hepatocyte fragility, and increased soluble phosphoglycokeratins in transgenic mice expressing a keratin 18 conserved arginine mutant. J. Cell Biol. 131: 1303-1314.

20. Abe, M., and R.G. Oshima. 1990. A single human keratin 18 gene is expressed in diverse epithelial cells of transgenic mice. J. Cell Biol. 111:1197-1206.

21. Liao, J., L.A. Lowthert, and M.B. Omary. 1995. Heat stress or rotavirus infection of human epithelial cells generates a distinct hyperphosphorylated form of keratin 8. Exp. Cell Res. 219:348-357.

22. Chou, C-F., and M.B. Omary. 1993. Mitotic-arrest associated enhancement of O-linked glycosylation and phosphorylation of human keratins 8 and 18. J. Biol. Chem. 268:4465-4472.

23. Chou, C-F., and M.B. Omary. 1994. Mitotic arrest with anti-microtubule agents or okadaic acid is associated with increased glycoprotein terminal GlcNAc's. J. Cell Sci. 107:1833-1843.

24. Liao, J., L.A. Lowthert, N-O. Ku, R. Fernandez, and M.B. Omary. 1995. Dynamics of human keratin 18 phosphorylation: polarized distribution of phosphorylated keratins in simple epithelial tissues. J. Cell Biol. 131:1291-1301.

25. Mallory, F.B. 1911. Cirrhosis of the liver. Five different types of lesions from which it may arise. Bull. Johns Hopkins Hosp. 22:69-75.

26. Denk, H., F. Gschnait, and K. Wolff. 1975. Hepatocellular hyalin (Mallory bodies) in long term griseofulvin-treated mice: a new experimental model for the study of hyalin formation. Lab. Invest. 32:773-776.

27. Barich, L.L., J. Schwarz, D.J. Barich, and M.G. Horowitz. 1961. Toxic liver damage in mice after prolonged intake of elevated doses of griseofulvin. Antibiot. Chemother. 11:566-571.

28. Weston Hurst, E., and G.E. Paget. 1963. Protoporphyrin, cirrhosis and hepatomata in the livers of mice given griseofulvin. Br. J. Dermatol. 75:105-112.

29. Salmhofer, H., I. Rainer, K. Zatloukal, and H. Denk. 1994. Post-translational events involved in griseofulvin-induced keratin cytoskeleton alterations. Hepatology. 20:731-740.

30. Cadrin, M., N. McFarlane Anderson, L.H. Aasheim, H. Kawahara, D.J. Franks, and S.W. French. 1995. Modifications in cytokeratin and actin in cultured liver cells derived from griseofulvin-fed mice. Lab. Invest. 72:453-460.

31. Kaplowitz, N. Drug metabolism and hepatotoxicity. 1992. In Liver and Biliary Diseases. N. Kaplowitz, editor. Williams and Wilkins, Baltimore, MD.

32. Farrell, GC. 1994. Drug-induced Liver Disease. Churchill Livingstone, Edinburgh, Scotland.

33. Zimmerman, HJ. Hepatotoxicity. 1993. Disease-A-Month 39:675-787.

34. Lee, W.M. Drug-induced hepatotoxicity. 1995. N. Engl. J. Med. 17: $1118-1127$.

35. Chou, C-F., A.J. Smith, and M.B. Omary. 1992. Characterization and dynamics of O-linked glycosylation of human cytokeratin 8 and 18. J. Biol. Chem. 267:3901-3906

36. Bray, G.P., J.M. Tredger, and R. Williams. 1992. S-Adenosylmethionine protects against acetaminophen hepatotoxicity in two mouse models. Hepatology. 15:297-301.

37. Yokoyama, H.O., M.E. Wilson, K.K. Tsuboi, and R.E. Stowell. 1953. Regeneration of mouse liver after partial hepatectomy. Cancer Res. 13:80-85.

38. Theocharis, S.E., A.S. Skopelitou, A.P. Margeli, K.J. Pavlaki, and C. Kittas. 1994. Proliferating cell nuclear antigen (PCNA) expression in regenerating rat liver after partial hepatectomy. Dig. Dis. Sci. 39:245-252.

39. Lowthert, L.A., N-O. Ku, J. Liao, P.A. Coulombe, and M.B. Omary. 1995. Empigen BB: a useful detergent for solubilization and biochemical analysis of keratins. Biochem. Biophys. Res. Comm. 206:370-379.

40. Laemmli, U.K. 1970. Cleavage of structural proteins during the assembly of the head of bacteriophage T4. Nature (Lond.). 227:680-685.

41. Ku, N-O., and M.B. Omary. 1995. Identification and mutational analysis of the glycosylation sites of human keratin 18. J. Biol. Chem. 270:11820-11827. 42. Steer, C.J. 1995. Liver regeneration. FASEB J. 9:1396-1400.

43. Higgins, G.M., and R.M. Anderson. 1931. Experimental pathology of the liver. Arch. Path. 12:186-202.

44. Wilson, M.E., R.E. Stowell, H.O. Yokoyama, and K.K. Tsuboi. 1953. Cytological changes in regenerating mouse liver. Cancer Res. 13:86-92.

45. Ku, N-O., and M.B. Omary. 1994. Identification of the major physiologic phosphorylation site of human keratin 18: potential kinases and a role in filament reorsanization. J. Cell Biol. 127:161-171.

46. Chan, Y.-M., Q.-C Yu, J.-D Fine, and E. Fuchs. 1993. The genetic basis of Weber-Cockayne epidermolysis bullosa simplex. Proc. Natl. Acad. Sci. USA. 90:7414-7418.

47. Morley, S.M., S.R. Dundas, J.L. James, T. Gupta, R.A. Brown, C.J. Sexton, H.A. Navsaria, I.M. Leigh, and E.B. Lane. 1995. Temperature sensitivity of the keratin cytoskeleton and delayed spreading of keratinocyte lines derived from EBS patients. J. Cell Sci. 108:3463-3471.

48. Arnaiz, S.L., S. Llesuy, J.C. Cutrin, and A. Boveris. 1995. Oxidative stress by acute acetaminophen administration in mouse liver. Free Radic. Biol. Med. 19:303-310. 
49. Denk, H., R. Eckerstorfer, R.E. Talcott, and J.B. Schenkman. 1977. Alteration of hepatic microsomal enzymes by griseofulvin treatment of mice. Biochem. Pharmacol. 26:1125-1130.

50. Amimoto, T., T. Matsura, S.-Y. Koyama, T. Nakanishi, K. Yamada, and G. Kajiyama. 1995. Acetaminophen-induced hepatic injury in mice: The role of lipid peroxidation and effects of pretreatment with coenzyme $\mathrm{Q}_{10}$ and $\alpha$-tocopherol. Free Radic. Biol. Med. 19:169-176.

51. Ku, N-O., J. Liao, C-F. Chou, and M.B. Omary. 1996. Implications of intermediate filament protein phosphorylation. Cancer \& Metastasis Rev. In press.
52. Haltiwanger, R.W., W.G. Kelly, E.P. Roquemore, M.A. Blomberg, L.-Y.D. Dong, L. Kreppel, T.-Y. Chou, and G.W. Hart. 1992. Glycosylation of nuclear and cytoplasmic proteins is ubiquitous and dynamic. Biochem. Soc. Trans. 20: 264-269.

53. Hart, G.W., K.D. Greis, L.-Y D. Dong, M.A. Blomberg, T-Y Chou, M-S Jiang, E.P. Roquemore, D.M. Snow, L.K. Kreppel, R.N. Cole, F.I. Comer, C.S Arnold, and B.K. Hayes. 1995. O-Linked N-acetylglucosamine: the "Yin-Yang" of ser/thr phosphorylation? Adv. Exp. Med. Biol. 376:115-123. 